\title{
EFFECT OF SELECTED ADDITIONS ON DE NOVO SYNTHESIS OF POLYCHLORINATED DIOXINS AND FURANS
}

\author{
WPŁYW WYBRANYCH DODATKÓW NA PRZEBIEG SYNTEZY DE NOVO \\ POLICHLOROWANYCH DIOKSYN I FURANÓW
}

\begin{abstract}
Polychlorinated dibenzo-p-dioxins and polychlorinated dibenzofurans are generally considered the most dangerous chemical substances known to man. Although they have never been the product of purposeful human activity, yet they are formed in many chemical and virtually all thermal processes. Research on the occurrence of dioxins in the environment, their release into the environment, ways of formation and methods of reducing their emissions lasts since the late seventies of the last century. Currently, we know three basic pathways of dioxins formation in thermal processes, the most important of them being the so called de novo synthesis which occurs outside the combustion zone at $200-400^{\circ} \mathrm{C}$ in the presence of catalysts ( $e g$ copper) and oxygen from the products of incomplete combustion including carbon black and chlorine or chlorinated compounds. It is well known that some metals like copper catalyze the de novo synthesis, while others decompose dioxins and furans formed previously. The formation of dioxins resulting from the de novo synthesis was studied through analysis of the effect of the type of metal on the course of the de novo synthesis. The influence of the addition of sulfur, nitrogen and alkali metals on this synthesis was also examined because some reports in the literature refer to inhibitory effect of these elements.
\end{abstract}

Keywords: dioxins and furans, PCDD/Fs, de novo synthesis, formation and inhibition

\section{Introduction}

In nature, all over the world, there are millions of chemical compounds and we are often unaware of their properties, including toxicity. Research conducted over the years helped determine toxicity of many of them, and also find ways to dispose them. Polychlorinated dibenzo-p-dioxins (PCDDs) and polychlorinated dibenzofurans (PCDFs) commonly referred to as dioxins are considered to be extremely dangerous for living organisms including humans [1,2]. Although they are present in the environment at low concentrations (often $10^{-8}-10^{-10} \mathrm{~g} / \mathrm{m}^{3}$ ), it was proved that they had a teratogenic effect and contributed to endocrine malfunction of the body and decreased activity of the immune system $[3,4]$. The main source of their emissions to the environment are considered to be

\footnotetext{
${ }^{1}$ Faculty of Process and Environmental Engineering, Lodz University of Technology, ul. Wólczańska 175, 90-924 Łódź, Poland, phone +48 4263137 95, fax +48 426368133

${ }^{2}$ Faculty of Chemistry, Cracow University of Technology, ul. Warszawska 24, 31-155 Kraków, Poland

* Corresponding author: grzegorz.wielgosinski@p.lodz.pl
} 
the processes of combustion ( $e g$ waste incineration) and also many other anthropogenic processes (eg chemical processes and metallurgy), but dioxins are formed also in many natural processes (eg forest fires, volcanic eruption) $[4,5]$.

Dioxins and furans are formed in every process of combustion of solid and liquid fuels in the presence of chlorine, oxygen and organic matter at appropriate temperatures [6]. There are three basic mechanisms of their formation described in the literature: high-temperature synthesis $\left(500-700^{\circ} \mathrm{C}\right)$ from chlorinated aromatic precursors [7], catalytic synthesis from chlorinated and non-chlorinated precursors and chlorinated compounds taking place at $300-500^{\circ} \mathrm{C}$ out of the combustion zone [8] and the most important one, the so-called de novo synthesis in which dioxins are formed outside the combustion zone from molecular carbon, carbonated residues from the combustion process, unburned carbon (in the form of dust and soot) and chlorine (both organic and inorganic) in the presence of volatile metals contained in the ash which catalyze the process (eg copper, zinc and aluminum) in the temperature range from 200 to $400^{\circ} \mathrm{C}$ [9]. There are many methods to reduce emissions of dioxins to the atmosphere which are described in detail in the literature $[10,11]$. Recently, the authors of many publications focused their attention on the reduction of dioxin emissions by reducing their formation according to the de novo mechanism. These substances include chemical compounds that comprise in their structure sulfur or nitrogen molecules and oxides as well as hydroxides of alkali metals. The mechanism of inhibition is not yet known in detail, but it is believed that it consists in decreasing the amount of free chlorine in the zone of de novo synthesis by changing it into other chemical compounds, less reactive or not participating in the reaction [12].

At present, the emission of dioxins is limited only for waste incineration plants. However, it should be taken into account that both Poland and the whole European Union (EU) are parties to the Stockholm Convention on persistent organic pollutants and as such they are obliged to a maximum reduction of PCDD/Fs release to the environment. The Stockholm Convention signed and ratified by Poland imposes on us the duty to systematically reduce the emissions of dioxins. It is therefore expected that emission limits will appear also for other economic activities. According to literature reports, in some EU countries such limits have been introduced (for metallurgical processes) and it is only a matter of time when they will hold throughout the EU [13].

\section{Materials and methods}

The aim of the study was to analyze the influence of selected chemical additives on the process of formation of dioxins according to the de novo mechanism. A set of chemical compounds considered in the literature as inhibitors of the de novo synthesis and transition metal compounds were examined. They are often used in catalytic oxidation or decomposition of organic compounds.

A magnetic stirrer with a heat-on block was used to carry out the process at $270-280^{\circ} \mathrm{C}$. Schematic of the set-up is shown in Figure 1.

In order to create conditions as close as possible to the real ones, the reaction mass was placed in glass tubes which were sealed with a SUPELCO adsorbing polyurethane foam (PUF). The prepared samples were then placed in the heat-on block. The reaction took approximately 4 hours. After cooling, the tubes were wrapped in aluminum foil and submitted for analysis. The whole content of the tubes, including PUF was analyzed. Determinations of 17 congeners of dioxins and furans in the tested samples were made 
according to the EN-1948 standard in the Trace Analysis Laboratory, Cracow University of Technology, accredited by the Polish Center for Accreditation in the area of determination of polychlorinated dibenzo-p-dioxins and dibenzofurans.

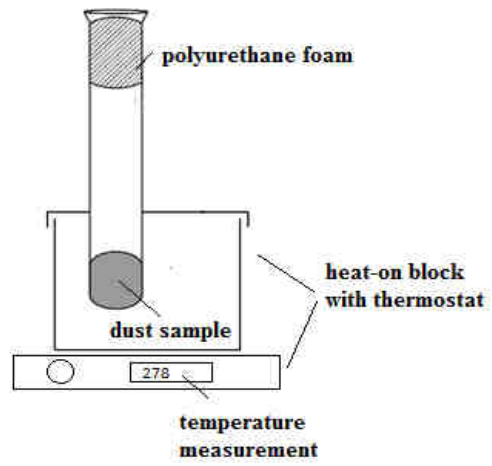

Fig. 1. Schematic of the experimental set-up

The composition of basic reaction mass was chosen so as to simulate the composition of fly ash from waste incineration processes, like in earlier works of Oberg et al [14], Ke et al [15], Chen et al [16], Fu et al [17] or Takaoka et al [18]. Average composition of the reaction mass in all experiments is shown in Table 1.

Table 1

Average composition of basic reaction mass

\begin{tabular}{|c|c|}
\hline Components & Percentage [\%] \\
\hline Activated carbon & 3.4 \\
\hline Graphite & 3.5 \\
\hline Silica & 79.3 \\
\hline Pentachlorophenol & 1.8 \\
\hline Trichlorophenol & 1.7 \\
\hline Potassium chloride & 6.9 \\
\hline Copper chloride & 3.4 \\
\hline Total: & 100.0 \\
\hline
\end{tabular}

The reaction mass with composition given in Table 1 , in an amount of about $2.9 \mathrm{~g}$ was supplemented in subsequent trials with approximately $0.2 \mathrm{~g}$ inhibitor or selected metal. The inhibitory effect of the following chemical compounds was investigated:

- $\quad$ Ammonium sulfate - $\left(\mathrm{NH}_{4}\right)_{2} \mathrm{SO}_{4}$

- Ammonium persulfate - $\left(\mathrm{NH}_{4}\right)_{2} \mathrm{~S}_{2} \mathrm{O}_{8}$

- Ammonium thiosulfate - $\left(\mathrm{NH}_{4}\right)_{2} \mathrm{~S}_{2} \mathrm{O}_{3}$

- $\quad$ Urea - $\left(\mathrm{NH}_{2}\right)_{2} \mathrm{CO}$

- Thiourea - $\left(\mathrm{NH}_{2}\right)_{2} \mathrm{CS}$

- $\quad$ Ammonium carbonate - $\left(\mathrm{NH}_{4}\right)_{2} \mathrm{CO}_{3}$

- $\quad$ Sodium sulfate - $\left(\mathrm{NH}_{4}\right)_{2} \mathrm{SO}_{4}$

- Sodium carbonate - $\mathrm{Na}_{2} \mathrm{CO}_{3}$

- $\quad$ Sodium bicarbonate - $\mathrm{NaHCO}_{3}$ 
- $\quad$ Sodium hydroxide - $\mathrm{NaOH}$

- Calcium hydroxide - $\mathrm{Ca}(\mathrm{OH})_{2}$

- Calcium carbonate - $\mathrm{CaCO}_{3}$

- Calcium oxide - $\mathrm{CaO}$

The catalytic effect of the following transition metal compounds on the de novo synthesis was also tested:

- $\quad$ Vanadium pentoxide $-\mathrm{V}_{2} \mathrm{O}_{5}$

- $\quad$ Tungsten trioxide $-\mathrm{WO}_{3}$

- Chromium trioxide $-\mathrm{Cr}_{2} \mathrm{O}_{3}$

- Molybdenum trioxide $-\mathrm{MoO}_{3}$

- Manganese oxide - $\mathrm{MnO}_{2}$

- $\quad$ Cobalt oxide $-\mathrm{Co}_{2} \mathrm{O}_{3}$

- Alumina oxide - $\mathrm{Al}_{2} \mathrm{O}_{3}$

- $\quad$ Zinc oxide - $\mathrm{ZnO}$

- $\quad$ Nickel oxide - $\mathrm{NiO}$

- Titanium dioxide - $\mathrm{TiO}_{2}$

- Ammonium molybdate - $\left(\mathrm{NH}_{4}\right)_{6} \mathrm{Mo}_{7} \mathrm{O}_{24} \cdot 4 \mathrm{H}_{2} \mathrm{O}$

- Ammonium tungstate - $\left(\mathrm{NH}_{4}\right)_{4} \mathrm{~W}_{5} \mathrm{O}_{17} \cdot 2.5 \mathrm{H}_{2} \mathrm{O}$

- Calcium titanate $-\mathrm{CaTiO}_{3}$

\section{Results and discussion}

\section{Effect of inhibition}

The analysis covered 13 chemical compounds containing sulfur and/or nitrogen atoms and also chemical alkaline compounds often used in flue gas purification to remove acid gases. The results were compared with results obtained for a sample without any inhibitor.

It was found that the synthesis resulted in formation of about $147000 \mathrm{ng}$ of a mixture of $17 \mathrm{PCDD} / \mathrm{Fs}$ congeners in the sample without inhibitors. In all samples with the inhibitor the amount of generated dioxins was reduced. Results of PCDD/Fs determination in the samples are shown in Figure 2.

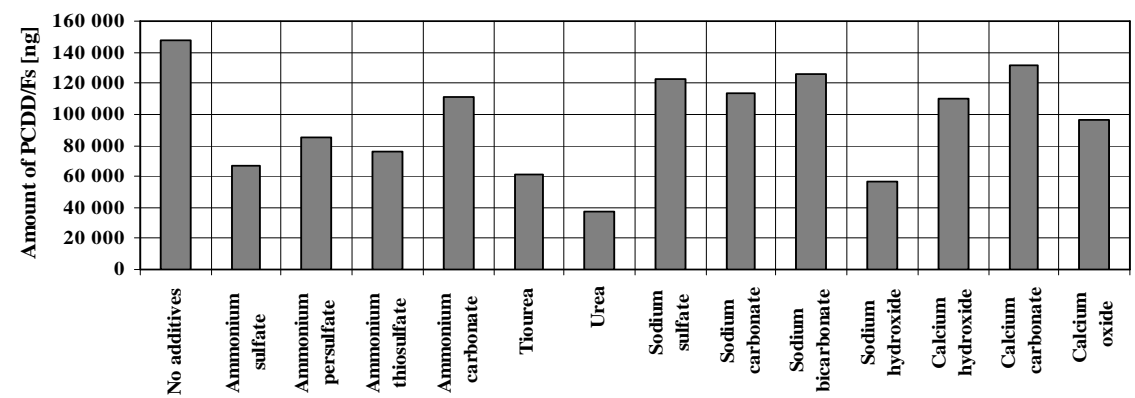

Fig. 2. Amount of PCDD/Fs determined in the tested samples

Additionally, to better illustrate the efficiency of selected inhibitors, Figure 3 shows PCDD/Fs reduction rates obtained in subsequent trials. The next diagram (Fig. 4) shows the 
efficiency of reduction of PCDD/Fs emissions per unit of inhibitor mass expressed in millimoles.

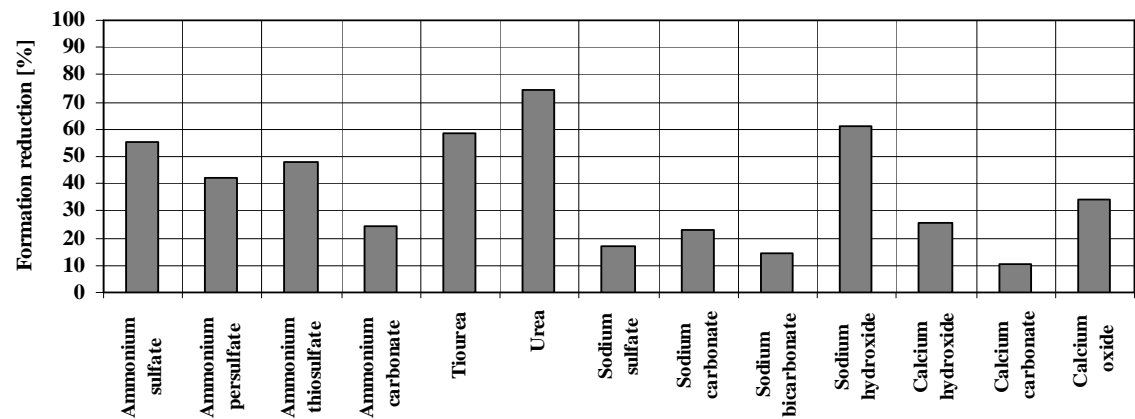

Fig. 3. Degree of reduction of formed PCDD/Fs obtained for individual PCDD/Fs inhibitors

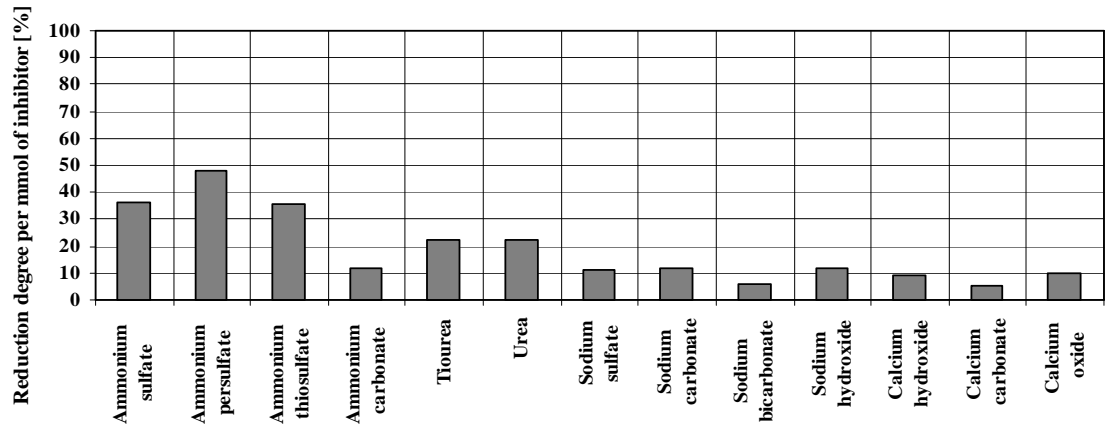

Fig. 4. Degree of reduction of formed PCDD/Fs vs. the amount of applied PCDD/Fs inhibitors

Analyzing the results it was observed that the highest degree of reduction of the quantities of dioxins and furans occur for the most chlorinated compounds which confirms literature reports that during the de novo synthesis there is a consecutive chlorination of molecules of formed dioxins. This also confirms the theory that the inhibitor action may consist in binding active chlorine capable of chlorination of benzene rings in the molecules of dioxin or furan in the de novo synthesis zone. The degrees of reduction in the synthesis of individual congeners are shown in Figure 5.

Based on the tests it can be concluded that all inhibitors selected for analysis demonstrated the ability of reducing the formation of PCDD/Fs in the samples. In comparison to the initial content of dioxins, urea showed the highest degree of dioxin reduction $\alpha$ in the sample reaching $74.4 \%$. High reduction degrees had also sodium hydroxide $-61.5 \%$ and thiourea $-58.3 \%$. Also ammonium compounds showed high degrees of PCDD/Fs reduction reaching 55\% for ammonium sulfate, $48.4 \%$ for ammonium thiosulfate and $42.4 \%$ for ammonium persulfate. However, referring reduction efficiency to the amount of inhibitor introduced into the process, expressed in millimoles, the highest inhibition efficiency was obtained for ammonium persulfate, next for ammonium sulfate 
and finally for thiosulfate, ie compounds which had most sulfur and nitrogen atoms in the molecule.

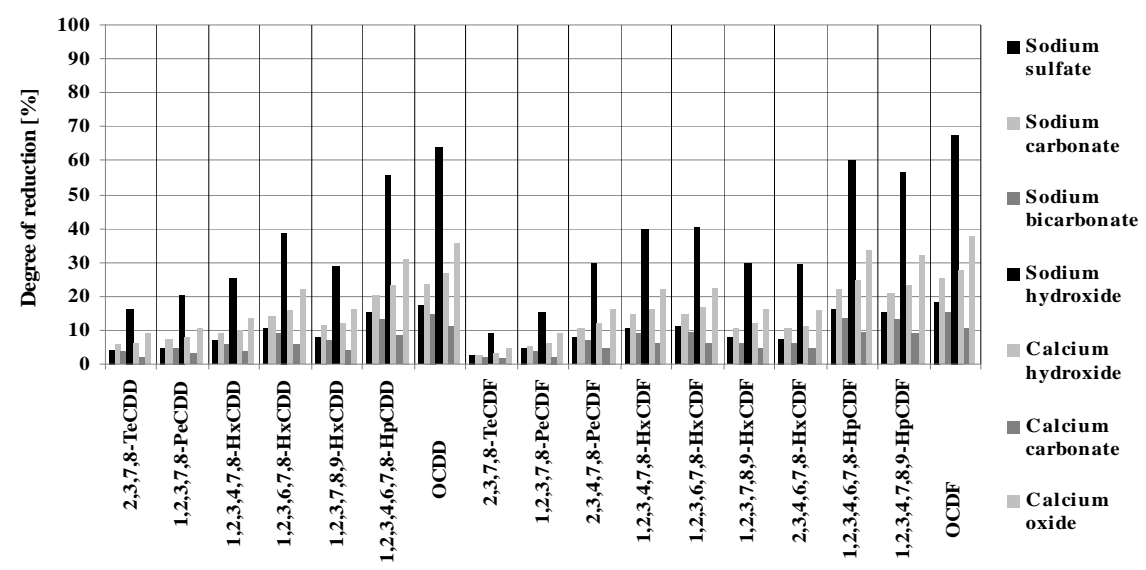

Fig. 5. Degree of the reduction of individual PCDD/Fs congeners $-\alpha$ for the tested inhibitors

\section{Effect of transition metals}

Second part of the research concerned the effect of transition metals on the formation of dioxins and furans during the de novo synthesis. Numerous publications have shown that some of the investigated metals - such as tungsten, vanadium and chromium (or rather their oxides) can perfectly decompose PCDD/Fs. On the other hand, it is also known that besides copper, aluminum and zinc are good catalysts of the de novo synthesis. However, in relation to other metals the literature reports are inconsistent. For example, some authors attribute to manganese or molybdenum the synthesis-supporting effect, while others point to their destructive nature.

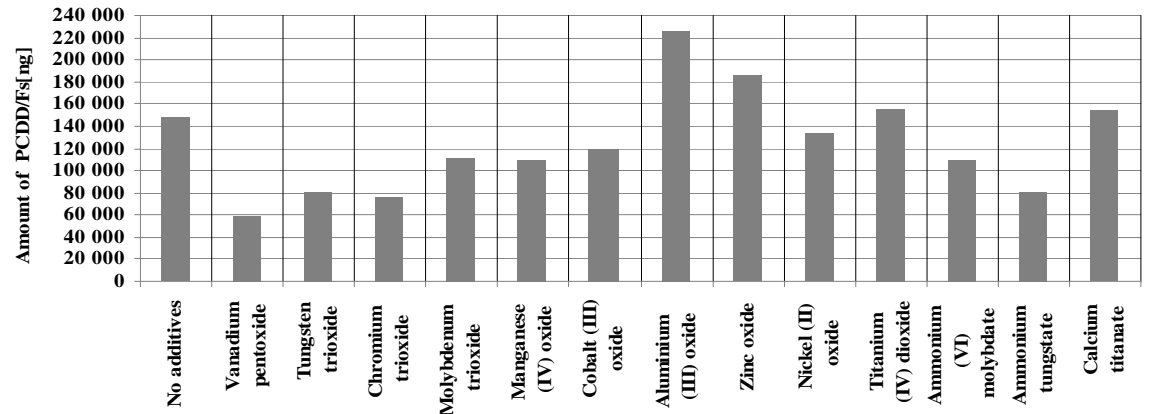

Fig. 6. Amount of PCDD/Fs determined in samples with metal addition

As a result of the studies and comparison of the amounts of dioxins obtained in particular samples with the addition of selected transition metal compounds and without such addition, an evident positive effect of aluminum and zinc and also a slightly positive 
impact of titanium compounds was found. Other metals showed negative effect, ie they caused a loss of the amount of dioxins in the samples, which means their decomposition. Figure 6 illustrates the amount of PCDD/Fs determined in the samples in the second part of the experiment - tests of the effect of selected transition metal compounds on the de novo synthesis.

As in the previous case, it was decided to analyze the loss of total PCDD/Fs mass in relation to the sample without additives and to determine in this way the degree of their reduction $-\alpha$. Results of this analysis are shown in Figure 7.

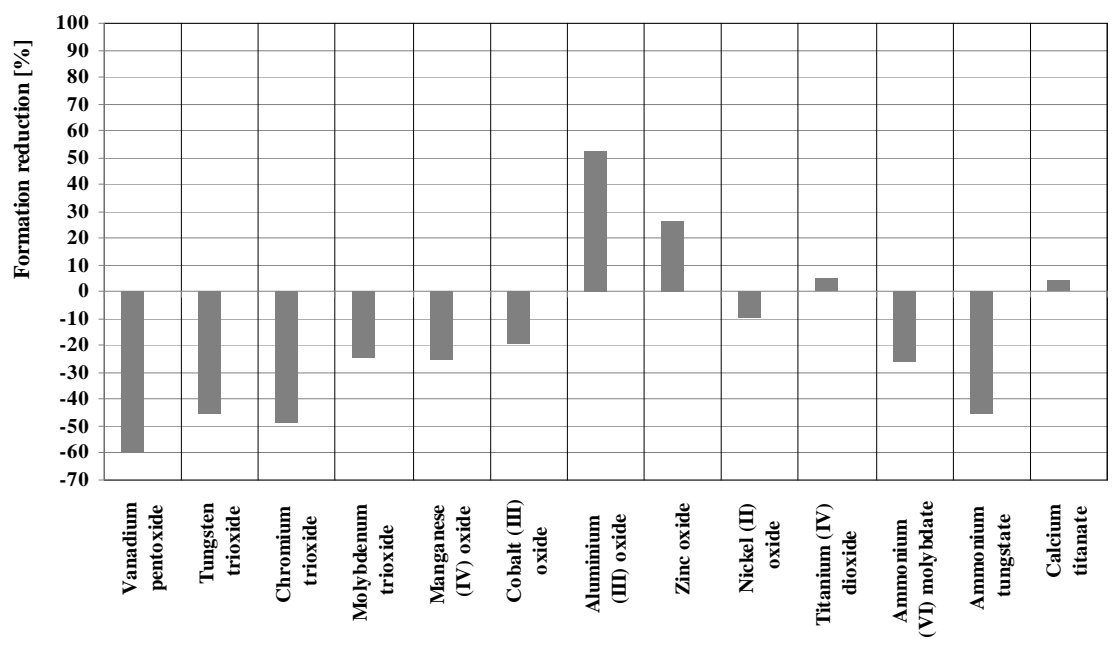

Fig. 7. Degree of reduction of formed PCDD/Fs for individual metals

Like in the case of inhibitors, while analyzing the results it was found that the highest degrees of reduction of the formed dioxins and furans occurred for the most chlorinated compounds which confirmed the literature reports indicating that during the de novo synthesis there was a consecutive chlorination of molecules of dioxins being formed, and the process of catalytic decomposition of dioxins consisted in the first stage in their consecutive dechlorination. Figure 8 shows the degree of reduction of the synthesis of individual congeners.

Studies have shown that the greatest reduction of dioxins and furans occurs while using vanadium oxide $(60 \%)$, tungsten compounds $(45 \%)$, chromium oxide $(48 \%)$ and the compounds of molybdenum $(25 \%)$ and manganese $(25 \%)$. When alumina $(-52.47 \%)$ and zinc oxide $(-26 \%)$ was used, the amount of dioxins in the samples increased as compared to the reference sample which means that these metals catalyze the synthesis of dioxins according to the de novo mechanism. On the other hand, titanium in the form of both calcium oxide and titanate has virtually no impact on the PCDD/Fs synthesis - a slight increase in the amount of formed dioxins was observed. However, it was interesting to find practically no differences between an oxide and its ammonium salt of both tungsten and molybdenum. 


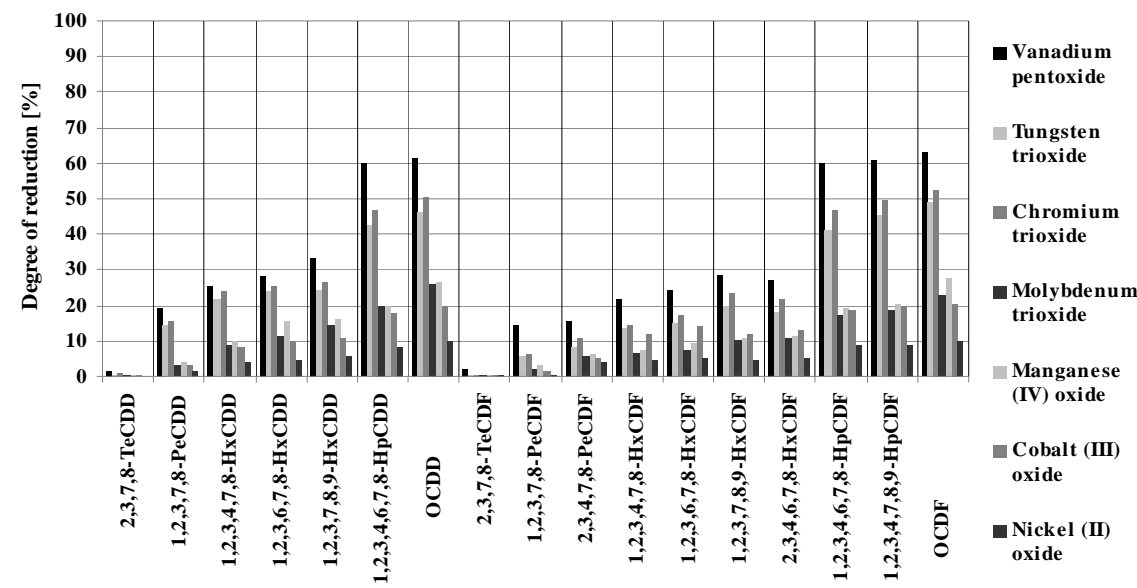

Fig. 8. Degrees of reduction of synthesis of individual PCDD/Fs congeners for tested metals

\section{Conclusions}

The aim of the study was to determine the inhibitory effect of tested substances on the reduction of dioxins emissions and to find relationships between molecular structure of the inhibitor and its reducing ability. Additionally, the effect of selected metals and their compounds on the de novo synthesis of polychlorinated dibenzo-p-dioxins and dibenzofurans was determined.

Analyzing the structure of selected inhibitors one can also observe a relationship between the amount of sulfur and nitrogen atoms occurring in the molecular structure of the inhibitor and its reducing ability. The inhibitors containing sulfur and nitrogen atoms in their structure reached much higher degrees of reduction than the compounds without these elements. The efficiency of reduction in reference to PCDD/Fs of subsequent compounds containing nitrogen and sulfur atoms can be classified approximately according to the principle that the more sulfur and nitrogen atoms in the molecular structure of the inhibitor the higher its reducing abilities.

In the case of tests carried out with the use of metal compounds (oxides), also the ability of reducing dioxins was observed. However, this is not an inhibitory effect but a result of parallel processes of catalytic decomposition of PCDD/Fs. Only aluminum and zinc showed catalytic activity which increased the efficiency of the de novo synthesis. Additionally, to compare the destructive effect of tungsten and molybdenum, their different forms were used. Experiments confirmed the hypothesis that in this case an important factor is metal and not its form. In both cases a high degree of reduction of the amount of PCDD/Fs was obtained. In the experiment with the use of titanium compounds practically neither a significant increase in the emissions of dioxins nor their reduction was observed.

Based on the studies it can be concluded that the method of reducing the emission of dioxins by means of chemical inhibitors and selected metals provides very large and real opportunities of its application in industrial practice. The possibility of inhibition and introduction of a metal which has an influence on the synthesis of dioxins by supplying small amounts of relatively cheap compounds to the stream of flue gases (at a suitable 
temperature) causes that it can be an economical alternative to other methods for removal of dioxins (eg as compared to the catalytic and adsorption methods).

\section{Acknowledgements}

This work was sponsored by the Voivideship Found for Environmental Protection and Water Management in Lodz (agreement: 834/BN/D/2014).

\section{References}

[1] Poland A, Knutson JC. 2,3,7,8-tetrachlorodibeno-p-dioxin and related halogenated aromatic hydrocarbons. Examination of the mechanism of toxicity. Annual Rev Pharmacol Toxicol. 1982;22:517-554. DOI: 10.1146/annurev.pa.22.040182.002505.

[2] Boening DW. Toxicity of 2,3,7,8-tetrachlorodibenzo-p-dioxin to several ecological receptor groups: a short review. Ecol Environ Safety. 1998;39:155-163. DOI: 10.1006/eesa.1997.1608.

[3] Cole P, Trichopoulos D, Pastides H, Starr T, Mandel JS. Dioxin and cancer: a critical review. Regulatory Toxicol Pharmacol. 2003;38(3):378-388. DOI: 10.1016/j.yrtph.2003.08.002.

[4] Wielgosiński G. Emisja dioksyn z procesów termicznych i metody jej ograniczania (Dioxin emissions from thermal processes and methods of emission reduction). Łódź: Polska Akademia Nauk (Polish Academy of Sciences); 2009.

[5] Rappe C. Sources of exposure, environmental concentrations and exposure assessment of PCDDs and PCDFs. Chemosphere. 1993;27:211-225. DOI: 10.1016/0045-6535(93)90295-G.

[6] Bumb RR., Crummett WB, Artie SS, Gledhill JR, Hummel RH, Kagel RO, et al. Trace chemistries of fire: a source of chlorinated dioxins. Science. 1980;210:385-390. DOI: 10.1126/science.6159682.

[7] Ballschmiter K, Zoller W, Buchert H, Clas Th. Correlation between substitution pattern and reaction pathway in the formation of polychlorodibenzofurans. Fresenius Zeit Analit Chem. 1985;322:587-594. DOI: 10.1007/BF00464594.

[8] Dickson LC, Karasek FW. Model studies of polychlorinated dibenzo-p-dioxin formation during municipal refuse incineration. Science. 1987;237:754-756. DOI: 10.1126/science.3616606.

[9] Vogg H, Stieglitz L. Thermal behavior of PCDD/PCDF in fly ash form municipal incinerators. Chemosphere. 1986;15:1373-1378. DOI: 10.1016/0045-6535(86)90412-1.

[10] Wielgosinski G. The possibilities of reduction of polychlorinated dibenzo-p-dioxins and polychlorinated dibenzofurans emission. Int J Chem Eng. 2010; Article ID 392175. DOI: 10.1155/2010/392175.

[11] McKay G. Dioxin characterization, formation and minimization during municipal solid waste (MSW) incineration. A Review. Chem Eng J. 2002;86:343-368. DOI: 10.1016/S1385-8947(01)00228-5.

[12] Ruokojärvi P, Asikainen A, Tuppurainen K, Ruuskanen J. Chemical inhibition of PCDD/F formation in incineration processes. Sci Total Environ. 2004;325:83-94. DOI: 10.1016/j.scitotenv.2003.11.006.

[13] Boscolo M, Padoano E, Tommasi S. Identification of possible dioxin emission reduction strategies in pre-existing iron ore sinter plants. Ironmaking Steelmaking. 2008;35:146-152. DOI: $10.1179 / 174328107$ X247815.

[14] Öberg T, Bergbäck B, Filipsson M. Catalytic effect by metal oxides on the formation and degradation of chlorinated aromatic compounds in fly ash. Chemosphere. 2008;71:135-1143. DOI: 10.1016/j.chemosphere.2007.10.033.

[15] Ke S, Jianhua Y, Xiaodong L, Shengyong L, Yinglei W, Muxing F. Inhibition of de novo synthesis of $\mathrm{PCDD} / \mathrm{Fs}$ by $\mathrm{SO}_{2}$ in a model system. Chemosphere. 2010;78:1230-1235. DOI: 10.1016/j.chemosphere.2009.12.043.

[16] Chen T, Zhan M, Lin X, Li X, Lu S, Yan J, et al. Inhibition of the de novo synthesis of PCDD/Fs on model fly ash by sludge drying gases. Chemosphere. 2014;114:226-232. DOI: 10.1016/j.chemosphere.2014.03.123.

[17] Fu JY, Li XD, Chen T, Lin XQ, Buekens A, Lu SY, et al. PCDD/Fs' suppression by sulfur-amine/ammonium $\quad$ compounds. $\quad$ Chemosphere. $\quad 2015 ; 123: 9-16$; DOI: 10.1016/j.chemosphere.2014.10.073.

[18] Takaoka M, Fujimori T, Shiono A, Yamamoto T, Takeda N, Oshita K, et al. Formation of chlorinated aromatics in model fly ashes using various copper compounds. Chemosphere. 2010;80:144-149. DOI: 10.1016/j.chemosphere.2010.04.005. 